\title{
PERBANDINGAN PENDUGA ORDINARY LEAST SQUARES (OLS) DAN GENERALIZED LEAST SQUARES (GLS) PADA MODEL REGRESI LINIER DENGAN REGRESOR BERSIFAT STOKASTIK DAN GALAT MODEL BERAUTOKORELASI
}

\author{
HELMI ISWATI, RAHMAT SYAHNI, MAIYASTRI \\ Program Studi Magister Matematika, \\ Fakultas Matematika dan Ilmu Pengetahuan Alam, Universitas Andalas, \\ Kampus UNAND Limau Manis Padang, Indonesia \\ helmi.iswati28@yahoo.com
}

\begin{abstract}
Abstrak. Pendugaan parameter model regresi linier pada analisis regresi linier, biasanya dilakukan dengan metode penduga OLS. Penduga OLS harus memenuhi asumsi-asumsi statistik yang disebut dengan asumsi klasik. Jika asumsi tidak dipenuhi, maka akan menghasilkan kesimpulan yang tidak valid sehingga penduga OLS tidak bisa digunakan lagi dalam melakukan pendugaan parameter. Oleh karena itu diperlukan metode pendugaan lain untuk memperoleh hasil yang valid yaitu penduga GLS. Pelanggaran asumsi diantaranya terdapat autokorelasi pada galat model dan regresor bersifat stokastik. Adanya autokorelasi dengan regresor bersifat stokastik dilihat melalui simulasi Monte Carlo dengan ukuran sampel, koefisien autokorelasi dan ulangan yang bervariasi. Selain itu, pendugaan parameter juga dievaluasi melalui beberapa kriteria yaitu nilai Absolut Bias, Varian dan MSE. Hasil simulasi menunjukkan bahwa semakin bertambahnya ukuran sampel mengakibatkan kriteria penduga parameter semakin kecil. Sementara itu, ulangan yang tinggi yang dilakukan pada simulasi ini tidak mempengaruhi kriteria penduga parameter. Pada pendugaan parameter model untuk semua penduga, penduga GLS lebih efisien dan stabil dibanding dengan penduga OLS kecuali untuk koefisen autokorelasi $-0.5 \leq \rho \leq-0.25$ dan $\rho=0.5$ pada $\widehat{\beta}_{1}$, dan $\rho=-0.25$ pada $\widehat{\beta}_{2}$.

Kata Kunci: Analisis Regresi Linier, Penduga OLS, Penduga GLS, Autokorelasi, Regresor Bersifat Stokastik
\end{abstract}

\section{Pendahuluan}

Analisis regresi adalah suatu metode statistika yang digunakan untuk menganalisa hubungan antara beberapa variabel. Model linier untuk pengamatan ke- $i$ secara umum ditulis sebagai berikut:

$$
Y_{i}=\beta_{0}+\beta_{1} X_{i 1}+\beta_{2} X_{i 2}+\ldots+\beta_{k} X_{i k}+u_{k} ; i=1,2, \cdots, n,
$$

dan dalam notasi matriks dapat ditulis sebagai

$$
\mathbf{Y}=\mathbf{X} \beta+\mathbf{u}
$$

Pendugaan parameter pada model liner regresi biasanya dilakukan dengan Metode Kuadrat Terkecil (MKT) atau disebut juga penduga Ordinary Least Squared (OLS). 
Penduga OLS pada model regresi linier mempunyai beberapa asumsi-asumsi yang harus dipenuhi, yaitu:

(1) $E\left(u_{i}\right)=0 ; i=1,2, \ldots, n$

Asumsi ini menyatakan bahwa nilai harapan dari $u_{i}$ adalah 0 .

(2) $\operatorname{Cov}\left(u_{i}, u_{j}\right)=E\left[u_{i}-E\left(u_{i}\right)\right]\left[u_{j}-E\left(u_{j}\right)\right]=E\left(u_{i} u_{j}\right)=0$

Asumsi ini menyatakan bahwa gangguan $u_{i}$ dan $u_{j}$ tidak berkorelasi atau tidak terdapat autokorelasi.

(3) $\operatorname{Var}\left(u_{i}\right)=E\left(u_{i}-E\left(u_{i}\right)\right)^{2}=E\left(u_{i}^{2}\right)=\sigma^{2}$

Asumsi ini menyatakan bahwa $u_{i}$ memiliki varian yang sama dan disebut dengan homoskedastisitas.

(4) $\operatorname{Cov}\left(u_{i}, X_{i}\right)=E\left[u_{i}-E\left(u_{i}\right)\right]\left[X_{i}-E\left(X_{i}\right)\right]=0$

Asumsi ini menyatakan bahwa gangguan $u$ dan regresor $X$ tidak berkorelasi.

(5) $\operatorname{Cor}\left(X_{i}, X_{j}\right)=0$

Asumsi ini menyatakan tidak adanya multikolinearitas diantara regresor.

(6) Regresor X bersifat tidak stokastik (fixed).

Penduga OLS harus memenuhi asumsi-asumsi statistik diatas. Jika asumsi tidak dipenuhi, maka akan menghasilkan kesimpulan yang tidak valid sehingga penduga OLS tidak bisa digunakan lagi dalam melakukan pendugaan parameter. Oleh karena itu diperlukan metode pendugaan lain untuk memperoleh hasil yang valid yaitu penduga GLS. Pelanggaran asumsi diantaranya terdapat autokorelasi pada galat model dan regresor bersifat stokastik dimana dapat dilihat melalui simulasi Monte Carlo.

\section{Penduga Ordinary Least Squares (OLS)}

Metode penduga Ordinary Least Squares (OLS) adalah metode pendugaan yang paling umum digunakan untuk menduga suatu model regresi populasi atas dasar model regresi sampel [5].

Prinsip pendugaan parameter dengan metode OLS adalah dengan meminimumkan jumlah kuadrat galat. Jika diberikan suatu model

$$
\mathbf{Y}=\mathbf{X} \beta+\mathbf{u}, E(\mathbf{u})=0 \text { dan } \operatorname{Var}(\mathbf{u})=\sigma^{2} \mathbf{I},
$$

maka diperoleh penduga OLS sebagai berikut

$$
\widehat{\beta}_{\text {ols }}=\left(\mathbf{X}^{\prime} \mathbf{X}\right)^{-1} \mathbf{X}^{\prime} \mathbf{Y}
$$

dimana nilai tengah dan varian dari penduga OLS adalah

$$
\begin{aligned}
E(\widehat{\beta}) & =\beta, \\
\operatorname{Cov}(\widehat{\beta}) & =\sigma^{2}\left(\mathbf{X}^{\prime} \mathbf{X}\right)^{-1} .
\end{aligned}
$$

\section{Penduga Generalized Least Squares (GLS)}

Pendugaan parameter koefisien dengan Generalized Least Squares (GLS) dalam masalah autokorelasi memiliki sebaran komponen galat dalam model tidak bebas 
lagi dan juga tidak identik. Dalam kasus ini, penduga OLS bersifat tak bias dan tidak konsisten [8].

Diberikan suatu model

$$
\mathbf{Y}=\mathbf{X} \beta+\mathbf{u}
$$

dengan $E(u)=0, \operatorname{Var}(u)=\sigma^{2} \boldsymbol{\Omega}$. Matriks $\boldsymbol{\Omega}$ adalah matriks simetris definit positif berorde $n \mathrm{x} n$ dan $\mathbf{u} \sim N\left(0, \sigma^{2} \boldsymbol{\Omega}\right)$. Penduga tak bias terbaik dari $\beta$ adalah

$$
\widehat{\beta}_{G L S}=\left(\mathbf{X}^{\prime} \mathbf{\Omega}^{-\mathbf{1}} \mathbf{X}\right)^{-\mathbf{1}} \mathbf{X}^{\prime} \mathbf{\Omega}^{-\mathbf{1}} \mathbf{Y},
$$

dimana nilai tengah dan matriks varian-kovarian dari penduga GLS adalah $E(\widehat{\beta})=$ $\beta$ dan $\operatorname{Cov}(\widehat{\beta})=\sigma^{2}\left(\mathbf{X}^{\prime} \mathbf{\Omega}^{-1} \mathbf{X}\right)^{-1}$.

\section{Autokorelasi}

Autokorelasi didefinisikan sebagai korelasi antara anggota serangkaian observasi yang diurutkan menurut waktu atau ruang (data cross section). Masalah autokorelasi muncul ketika salah satu asumsi klasik tidak terpenuhi, yaitu

$$
\operatorname{Cov}\left(u_{i}, u_{j}\right) \neq 0 \text { dan } i=1,2, \cdots, n .
$$

Metode yang biasa digunakan untuk kasus autokorelasi adalah dengan mengasumsikan gangguan $u_{t}$ mengikuti proses autoregresif. Autoregresif orde satu (FirstOrder Autoregressive) adalah pola autoregresif yang paling umum digunakan untuk masalah pelanggaran asumsi ini [9]. Autoregresif orde satu yang dinotasikan dengan $\mathrm{AR}(1)$, ditulis sebagai berikut

$$
u_{t}=\rho u_{t-1}+\varepsilon_{t} ; t=1,2, \cdots, T ; \varepsilon_{t} \sim\left(0, \sigma^{2}\right) \text { dan }|\rho|<1,
$$

$\varepsilon_{t}$ diasumsikan mempunyai nilai tengah nol, varian konstan dan kovarian nol. Bentuk umum dari $\operatorname{AR}(1)$ adalah:

$$
u_{t}=\sum_{r=0}^{\infty} \rho^{r} \varepsilon_{t-r}
$$

dengan nilai tengah $u_{t}$ adalah $E\left(u_{t}\right)=0$, varian $u_{t}$ adalah $\operatorname{Var}\left(u_{t}\right)=\frac{\sigma_{\varepsilon}^{2}}{1-\rho^{2}}=\sigma_{u}^{2}$, dan kovarian $u_{t}$ yaitu $E\left(u_{t} u_{t-s}\right)=\rho^{s} \sigma_{u}^{2}$; untuk $s \neq 0$.

Bentuk matriks varian-kovarian dari $\mathbf{u}$ adalah

$$
\operatorname{Var}(\mathbf{u})=E\left(\mathbf{u} \mathbf{u}^{\prime}\right)=\sigma_{\mathbf{u}}^{2}\left[\begin{array}{ccccc}
1 & \rho & \rho^{2} & \cdots & \rho^{n-1} \\
\rho & 1 & \rho & \cdots & \rho^{n-2} \\
\vdots & \vdots & \vdots & \ddots & \vdots \\
\rho^{n-1} & \rho^{n-2} & \rho^{n-3} & \cdots & 1
\end{array}\right]=\sigma^{2} \boldsymbol{\Omega}
$$

dan invers dari matriks definit positif $\boldsymbol{\Omega}$ adalah

$$
\boldsymbol{\Omega}^{-\mathbf{1}}=\frac{1}{1-\rho^{2}}\left[\begin{array}{ccccccc}
1 & -\rho & 0 & \cdots & 0 & 0 & 0 \\
-\rho & 1+\rho^{2} & -\rho & \cdots & 0 & 0 & 0 \\
\vdots & \vdots & \vdots & \cdots & \vdots & \vdots & \vdots \\
0 & 0 & 0 & \cdots & -\rho & 1+\rho^{2} & -\rho \\
0 & 0 & 0 & \cdots & 0 & -\rho & 1
\end{array}\right]
$$




\section{Metodologi Penelitian}

Penelitian dilakukan melalui simulasi Monte Carlo menggunakan software matlab 5.3 dengan data terdistribusi normal dan eksponensial yang terdiri dari 10, 20, 30, 40 dan 50 buah data. Langkah-langkah simulasi yang dilakukan adalah sebagai berikut:

(1) Lakukan fungsi penginputan nilai

- Banyak observasi (n)

- Banyak ulangan (R)

(2) Buat model regresi linear dimana $\mathrm{X}$ stokastik dan gangguan $u$ mengikuti pola autoregresif orde satu (first-order autoregressive), yaitu

$$
y_{t}=\beta_{0}+\beta_{1} x_{1 t}+\beta_{2} x_{2 t}+u_{t} ; t=1, n
$$

dengan $u_{t}=\rho u_{t-1}+\varepsilon_{t} ;|\rho|<1$ dan $\varepsilon_{t} \sim N\left(0, \sigma^{2}\right)$

(3) Bangkitkan $x_{1 t}$ dan $x_{2 t}$ secara acak mengikuti sebaran normal dengan nilai tengah nol dan varian satu dan mengikuti sebaran eksponensial dengan nilai parameter dua.

(4) Bangkitkan $u_{t}$ dengan $u_{t}=\rho u_{t-1}+\varepsilon_{t} ;|\rho|<1$ dan $\varepsilon_{t} \sim N\left(0, \sigma^{2}\right)$ yang berautokorelasi pada model linier $y_{t}$ dengan langkah sebagai berikut:

- Bangkitkan secara acak nilai $\varepsilon_{t}$ mengikuti sebaran normal dengan nilai tengah nol dan varian satu, $\varepsilon_{t} \sim N(0,1)$

- Tetapkan $u_{0}=1$

- Hitung $u_{t}=\rho u_{t-1}+\varepsilon_{t} ; t=2,, n$

Sudah terlihat bahwa $u_{t}$ berautokorelasi mengikuti pola $\operatorname{AR}(1)$.

(5) Hitung $y_{t}=\beta_{0}+\beta_{1} x_{1 t}+\beta_{2} x_{2 t}+u_{t}$ dengan menetapkan $\beta_{0}=\beta_{1}=\beta_{2}=2$

(6) Gunakan data simulasi tersebut untuk melakukan pendugaan dengan penduga GLS dan OLS sebagai berikut

- Hitung $\widehat{\beta}_{G L S}=\left(X^{\prime} \Omega^{-1} X\right)^{-1} X^{\prime} \Omega^{-1} y$

- Hitung $\widehat{\beta}_{\text {ols }}=\left(X^{\prime} X\right)^{-1} X^{\prime} y$

(7) Ulangi pendugaan parameter sebanyak $\mathrm{R}$ kali ulangan

(8) Hitung rata-rata $\widehat{\beta}_{0}, \widehat{\beta}_{1}, \widehat{\beta}_{2}$, untuk masing-masing penduga GLS dan OLS:

$$
\widehat{\widehat{\beta}}_{i}=\frac{1}{R} \sum_{j=1}^{R} \widehat{\beta}_{i j}
$$

untuk variabel ke- $i=0,1,2$ dan ulangan ke- $j=1,2, \cdots, R$

(9) Hitung Nilai dari masing-masing penduga GLS dan OLS

- Absolut Bias, yaitu $B\left(\widehat{\beta}_{i}\right)=\frac{1}{R} \sum_{j=1}^{R}\left|\widehat{\beta}_{i j}-\beta_{i}\right|$

- $\operatorname{Var}\left(\widehat{\beta}_{i}\right)=\frac{1}{R} \sum_{j=1}^{R}\left(\widehat{\beta}_{i j}-\overline{\widehat{\beta}}_{i j}\right)^{2}$

- $\operatorname{MSE}\left(\widehat{\beta}_{i}\right)=\frac{1}{R} \sum_{j=1}^{R}\left(\widehat{\beta}_{i j}-\beta_{i}\right)^{2}=\operatorname{Var}\left(\widehat{\beta}_{i}\right)+\left[B\left(\widehat{\beta}_{i}\right)\right]^{2}$ untuk $i=0,1,2$ dan $j=1,2, \cdots, R$

(10) Tampilkan output dugaan parameter untuk $\beta_{0}, \beta_{1}, \beta_{2}$ dengan ulangan (R) yang dilakukan sebanyak 100, 500 dan 1000 kali, dengan nilai koefisien autokorelasi sebagai berikut: $0.99,0.75,0.5,0.25,-0.25,-0.5,-0.75$, dan -0.99 . 
(11) Buat grafik dan analisis dari hasil simulasi yang menerangkan tentang pengaruh koefisien autokorelasi, ukuran sampel dan ulangan yang bervariasi terhadap penduga parameter model.

\section{Hasil Simulasi}

Hasil dari simulasi pendugaan parameter model regresi linier terhadap $\widehat{\beta}_{0}, \widehat{\beta}_{1}, \widehat{\beta}_{2}$ melalui simulasi Monte Carlo ditunjukkan dalam bentuk diagram garis untuk beberapa koefisien autokorelasi $(\rho)$ dan diagram garis untuk koefisien lainnya dapat dilihat pada gambar terlampir. Diagram garis dapat disajikan sebagai berikut:

\subsection{Pengaruh Ukuran Sampel (n) dan Koefisien Autokorelasi ( $\rho)$ terhadap Penduga Parameter dengan Regresor Terdistribusi Normal}

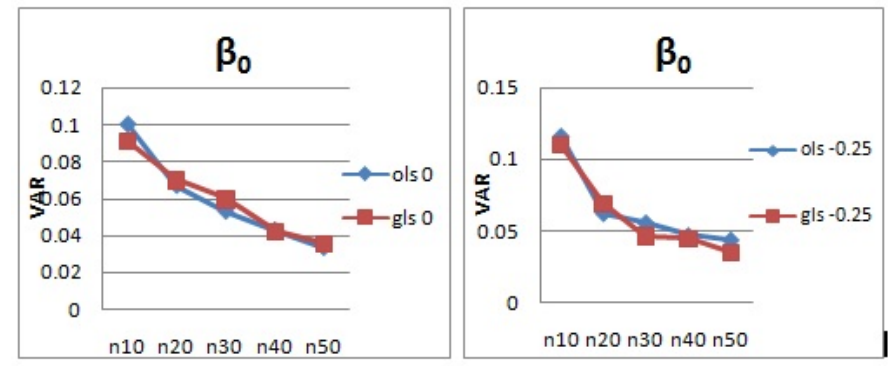

Gambar 1. Nilai Varian $\beta_{0}$ GLS dan OLS.

Gambar 1 menunjukkan nilai varian dari $\beta_{0}$ penduga GLS dan OLS untuk koefisien autokorelasi $(\rho)$ yang berbeda-beda. Nilai varian $\beta_{0}$ OLS dan $\beta_{0}$ OLS pada kedua koefisien autokorelasi terlihat bergerak untuk masing-masing garis dengan ukuran sampel yang semakin besar menuju titik nol. Pada grafik di atas terlihat bahwa nilai varian $\beta_{0}$ OLS lebih kecil dari pada nilai varian $\beta_{0}$ GLS untuk koefisien 0 . Nilai varian $\beta_{0}$ GLS lebih kecil dan stabil dari pada nilai varian $\beta_{0}$ OLS untuk koefisien -0.25 .

Gambar 2 menunjukkan nilai MSE dari $\beta_{0}$ penduga GLS dan OLS untuk koefisien autokorelasi $(\rho) 0.25$ dan -0.75. Nilai MSE $\beta_{0}$ OLS dan GLS untuk kedua koefisen autokorelasi terlihat bergerak menuju titik nol dengan semakin bertambahnya ukuran sampel (n). Pada grafik di atas juga dapat dilihat bahwa nilai MSE $\beta_{0}$ GLS lebih kecil dan stabil dari pada nilai MSE $\beta_{0}$ OLS untuk kedua nilai koefisien autokorelasi $(\rho)$ dan hal yang sama juga diperlihatkan untuk koefisien autokorelasi lainnya pada gambar terlampir.

Secara keseluruhan, pengaruh koefisien autokorelasi terhadap kriteria penduga parameter dapat disajikan dalam bentuk tabel sebagai berikut: 


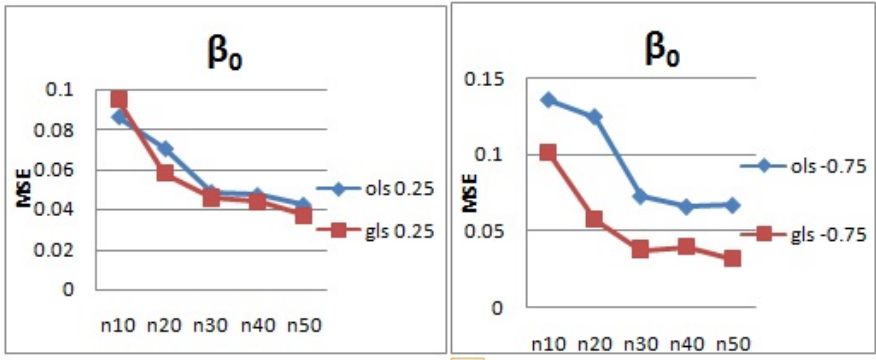

Gambar 2. Nilai MSE $\beta_{0}$ GLS dan OLS.

\begin{tabular}{|c|c|l|c|c|c|}
\hline No & Penduga & Kriteria & GLS < OLS & GLS = OLS & GLS > OLS \\
\hline \multirow{3}{*}{1} & \multirow{2}{*}{$\hat{\beta}_{0}$} & Abs. Bias & 8 & - & - \\
\cline { 3 - 6 } & & Varian & 8 & - & - \\
\cline { 3 - 6 } & & MSE & 8 & - & - \\
\hline \multirow{3}{*}{2} & \multirow{3}{*}{$\hat{\beta}_{1}$} & Abs. Bias & 6 & - & 2 \\
\cline { 3 - 6 } & & Varian & 8 & - & - \\
\cline { 3 - 6 } & & MSE & 7 & - & 1 \\
\hline \multirow{3}{*}{3} & \multirow{2}{*}{$\hat{\beta}_{2}$} & Abs. Bias & 7 & - & 1 \\
\cline { 3 - 6 } & Varian & 8 & - & - \\
\cline { 3 - 6 } & \multicolumn{2}{|c|}{ Total } & 8 & - & - \\
\hline & \multicolumn{2}{|c|}{ MSE } & 68 & - & 4 \\
\hline
\end{tabular}

\subsection{Pengaruh Ulangan (R) terhadap Penduga Parameter}

Pada bagian ini akan dilihat pengaruh ulangan terhadap penduga parameter model linier pada kriteria varian yang dilakukan sebanyak 100, 500 dan 1000 kali.

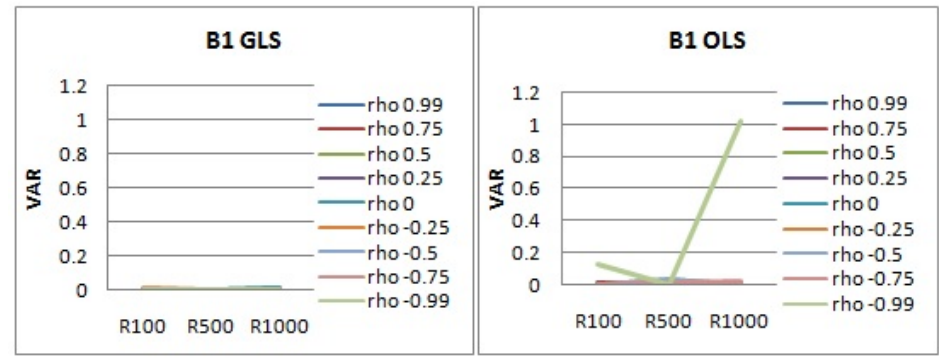

Gambar 3. ulangan pada nilai Varian $\beta_{1}$ GLS dan OLS.

Pada Gambar 3 menunjukkan pengaruh ulangan pada nilai varian $\beta_{1}$ GLS dan $\beta_{1}$ OLS dengan regresor terdistribusi normal. Nilai varian pada $\beta_{1}$ GLS terlihat meningkat pada garis dengan koefisien $0.5,0,-0.5$ namun nilainya tidak terlalu besar. Hal yang sama juga terlihat pada $\beta_{1}$ OLS, nilai varian meningkat pada koefisien 0.5 dan tidak terlalu berpengaruh pada koefisien lainnnya. 


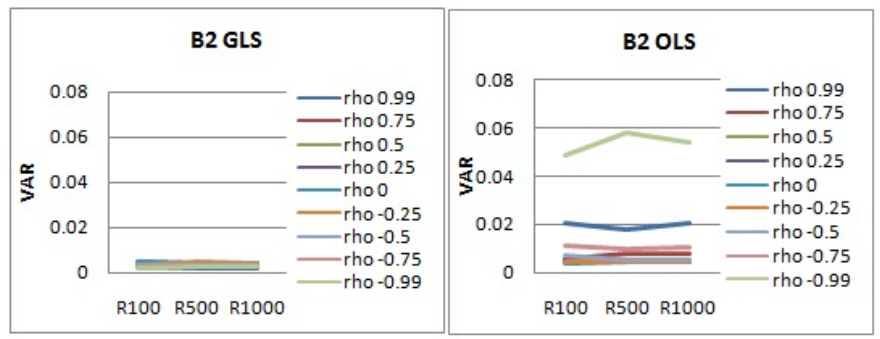

Gambar 4. ulangan pada nilai Varian $\beta_{2}$ GLS dan OLS.

Pada Gambar 4 menunjukkan nilai varian pada masing-masing penduga parameter bergerak tidak terlalu signifikan seiring meningkatnya ulangan. Artinya ulangan yang dilakukan tidak terlalu mempengaruhi penduga parameter.

\subsection{Pengaruh Ukuran sampel (n) dan Koefisien Autokorelasi ( $\rho$ ) terhadap Penduga Parameter dengan Regresor Terdistribusi Eksponensial}

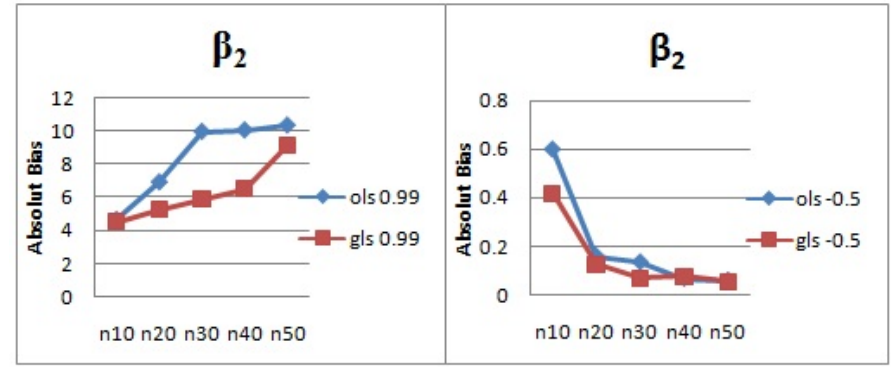

Gambar 5. Nilai Absolut Bias $\beta_{2}$ GLS dan OLS Eksponensial.

Gambar 5 menunjukkan nilai absolut bias dari $\beta_{2}$ penduga GLS dan OLS untuk koefisien autokorelasi $(\rho)$ yang berbeda-beda. Nilai absolut bias $\beta_{2}$ OLS dan $\beta_{2}$ GLS pada koefisien -0.5 terlihat bergerak menuju titik nol dengan ukuran sampel yang semakin besar. Sementara koefisien 0.99, nilai absolut bias bergerak naik seiring bertambahnya ukuran sampel. Pada grafik di atas juga terlihat bahwa untuk kedua koefisien, nilai absolut bias $\beta_{2}$ GLS lebih kecil dari pada nilai absolut bias $\beta_{2}$ OLS dan hal yang sama juga digambarkan pada koefisien lainnya dimana dapat dilihat pada gambar terlampir.

Gambar 6 menunjukkan nilai varian dari $\beta_{2}$ penduga GLS dan OLS untuk koefisien 0.5 dan -0.75 terlihat bergerak menuju titik nol seiring ukuran sampel yang semakin besar. Pada grafik di atas juga terlihat bahwa untuk kedua koefisien, nilai varian $\beta_{2}$ GLS lebih kecil dan stabil dari pada nilai varian $\beta_{2}$ OLS hal yang sama juga digambarkan pada koefisien lainnya dimana dapat dilihat pada lampiran. 


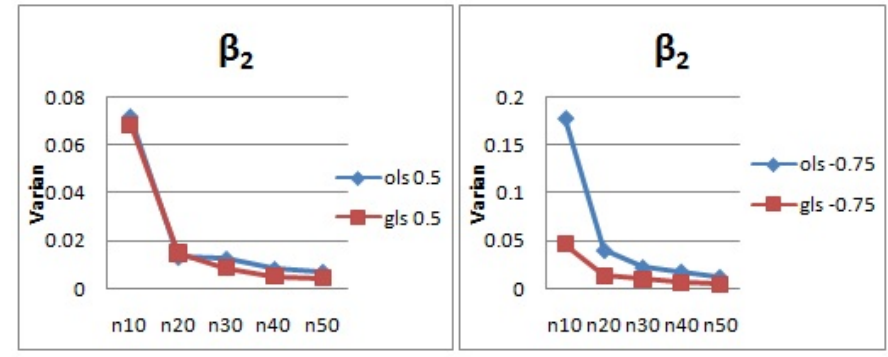

Gambar 6. Nilai Varian $\beta_{2}$ GLS dan OLS Eksponensial.

Secara keseluruhan, pengaruh koefisien autokorelasi terhadap kriteria penduga parameter untuk regresor terdistribusi eksponensial dapat disajikan dalam bentuk tabel sebagai berikut:

\begin{tabular}{|c|c|l|c|c|c|}
\hline No & Penduga & Kriteria & GLS < OLS & GLS = OLS & GLS > OLS \\
\hline \multirow{3}{*}{1} & \multirow{3}{*}{$\hat{\beta}_{0}$} & Abs. Bias & 7 & - & 1 \\
\cline { 3 - 6 } & & Varian & 8 & - & - \\
\cline { 3 - 6 } & & MSE & 8 & - & - \\
\hline \multirow{3}{*}{2} & \multirow{3}{*}{$\hat{\beta}_{1}$} & Abs. Bias & 5 & - & 3 \\
\cline { 3 - 6 } & Varian & 6 & - & 2 \\
\cline { 3 - 6 } & & MSE & 7 & - & 1 \\
\hline \multirow{3}{*}{3} & \multirow{2}{*}{$\hat{\beta}_{2}$} & Abs. Bias & 8 & - & - \\
\cline { 3 - 6 } & Varian & 8 & - & - \\
\cline { 3 - 6 } & & MSE & 7 & - & 1 \\
\hline \multicolumn{2}{|c|}{ Total } & 64 & - & 8 \\
\hline
\end{tabular}

\section{Kesimpulan}

Hasil percobaan simulasi Monte Carlo menunjukkan bahwa pada masing-masing penduga, nilai Absolut Bias, Varian dan MSE akan semakin kecil seiring dengan bertambahnya ukuran sampel $(n)$. Sementara itu, ulangan $(\mathrm{R})$ yang dilakukan sebanyak 100, 500, dan 1000 kali menunjukkan bahwa ulangan yang cukup besar tidak terlalu mempengaruhi penduga parameter model. Adanya autokorelasi pada model mempengaruhi kriteria penduga parameter. Simulasi yang dilakukan dengan regresor terdistribusi eksponensial menunjukkan bahwa nilai koefisien autokorelasi juga mempengaruhi kriteria penduga parameter model. Namun, hal ini tidak jauh berbeda dengan hasil simulasi dengan regresor terdistribusi normal. Dengan demikian, pada pendugaan parameter model untuk semua penduga $\widehat{\beta}_{0}, \widehat{\beta}_{1}$, dan $\widehat{\beta}_{2}$, penduga GLS lebih efisien dan stabil dibanding dengan penduga OLS kecuali untuk koefisen autokorelasi $-0.5 \leq \rho \leq-0.25$ dan $\rho=0.5$ pada $\widehat{\beta}_{1}$, dan $\rho=-0.25$ pada $\widehat{\beta}_{2}$. 


\section{Ucapan Terima Kasih}

Penulis mengucapkan terima kasih kepada Bapak Prof. Dr. Ir. H. Rahmat Syahni, M.S, M.Sc, dan Ibuk Dr. Maiyastri selaku pembimbing serta Bapak Dr. Muhafzan, Bapak Dr. Admi Nazra, Bapak Dr. Dodi Devianto dan Ibuk Dr. Ferra Yanuar yang telah banyak memberikan bimbingan, masukan dan saran sehingga Jurnal ini dapat diselesaikan dengan baik.

\section{Daftar Pustaka}

[1] Ayinde Kayode, Akintol Ladoke dan Olaomi, J.O. 2008. Robustness of Some Estimators of Linear Model with Autocorrelated Error Terms When Stochastic Regressors are Normally Distributed. Journal of Modern Applied Statistical Methods, 7(1), $246-252$

[2] Bain, L.J. dan Engelhardt. 1992. Introduction to Probability and Mathematical Statistics, 2nd ed. Duxbury Press.California.

[3] Baltagi, Badi.H. 2008. Econometrics. Springer-Verlag. Berlin.

[4] Feracchi, Franco. 2001. Econometrics. Chichester. England

[5] Gujarati, Damodar. 1997. Ekonometrika Dasar. Penerbit Erlangga, Jakarta

[6] Hamilton, James D. 1994. Time Series Analysis. Princeton University Press. United Kingdom

[7] Johnston, J. 1972. Econometric Methods. McGraw-Hill. New York.

[8] Juanda, Bambang. 2009. Ekonometrika: Pemodelan dan Pendugaan. IPB Press. Bogor

[9] Ramanathan, Ramu. 1993. Statistical Methods in Econometrics. Academis Press, Inc, New York

[10] Rubinstein, Reuven Y. 1981. Simulation and the Monte Carlo Method. John Wiley and Sons,Inc. Canada 